\title{
Diagnosis and follow-up value of endoscopic ultrasonography (EUS) in primary gastric non-Hodgkin's lymphoma
}

\author{
Rong Fan ${ }^{1 \#}$, Tianyu Zhang ${ }^{1 \#}$, Xiangyi He ${ }^{1}$, Wei Wu ${ }^{1}$, Tingting Gong ${ }^{1}$, Haiyang Lu $^{2}$, Shu Cheng ${ }^{2}$, \\ Huijuan Zhong $^{2}$, Weiguo Cao ${ }^{3}$ \\ ${ }^{1}$ Department of Gastroenterology, Ruijin Hospital, Shanghai Jiaotong University School of Medicine, Shanghai, China; ${ }^{2}$ Department of Hematology, \\ Ruijin Hospital, Shanghai Jiaotong University School of Medicine, Shanghai, China; ${ }^{3}$ Department of Radiation Oncology, Ruijin Hospital, Shanghai \\ Jiaotong University School of Medicine, Shanghai, China \\ Contributions: (I) Conception and design: W Cao; (II) Administrative support: W Cao; (III) Provision of study materials or patients: H Lu, S Cheng, \\ H Zhong, W Cao; (IV) Collection and assembly of data: R Fan, T Zhang, X He, W Wu, T Gong; (V) Data analysis and interpretation: R Fan, X He, \\ H Lu; (VI) Manuscript writing: All authors; (VII) Final approval of manuscript: All authors. \\ \#These authors contributed equally to this work. \\ Correspondence to: Weiguo Cao. Department of Radiation Oncology, Ruijin Hospital, Shanghai Jiaotong University School of Medicine, Shanghai, \\ China. Email: caoweiguo52@hotmail.com.
}

Background: The lesion of primary gastric non-Hodgkin's lymphoma (PGL) originates from the submucosa, so conventional gastroscopy has limited diagnostic potential. This study evaluated the diagnosis and follow-up value of endoscopic ultrasonography (EUS) in PGL.

Methods: Seventy-nine patients diagnosed with PGL either by EUS and biopsy pathology or by postoperative pathology were included in the study. All subjects underwent EUS with deep targeted biopsy and regular follow-up.

Results: We found sensitivity and specificity of EUS combined with deep targeted biopsy for PGL as $87.3 \%$ (69/79) and $80.0 \%$ (20/25) respectively, and the diagnostic accuracy as $85.6 \%(89 / 104)$. EUS combined with deep targeted biopsy had significantly greater diagnostic accuracy than gastroscopy $[85.6 \%(89 / 104) v s$. $57.7 \%(60 / 104) ;(\mathrm{P}<0.001)]$. The diagnostic accuracy of $\mathrm{T}$ tumor staging and $\mathrm{N}$ tumor staging of EUS were $13 / 13$ and 11/13 respectively compared with postoperative staging. The mean time of complete remission of lymphoma after eradication treatment in the H. pylori-negative (successful eradication) group ( $3.2 \pm 0.7$ months) was shorter than that in H. pylori-positive patients (failed eradication) group ( $4.5 \pm 0.8$ months), there was statistically significant difference between the two groups $(\mathrm{t}=4.3, \mathrm{P}<0.001)$.

Conclusions: This study demonstrated that EUS combined with deep targeted biopsy was associated with increased detection of Primary gastric non-Hodgkin's lymphoma (PGL), in terms of depth and extent of the lesion to guide treatment selection and to evaluate treatment efficacy.

Keywords: Primary gastric non-Hodgkin's lymphoma (PGL); endoscopic ultrasonography (EUS); deep targeted biopsy

Submitted Jul 05, 2020. Accepted for publication Jan 29, 2021.

doi: $10.21037 /$ tcr-20-2459

View this article at: http://dx.doi.org/10.21037/tcr-20-2459

\section{Introduction}

Primary gastric lymphoma (PGL), representing 5\% of gastric malignancies is generally non-Hodgkin lymphomas (NHL). It accounts for $30 \%$ to $45 \%$ of NHL (1). Two histological types are particularly frequent in primary extranodal presentations diffuse large B-cell lymphomas and marginal zone B-cell lymphomas of the Mucosa-Associated Lymphoid Tissue (MALT-type) (2). Mantle cell, follicular and peripheral T-cell lymphomas are rare types $(3,4)$. It is 
believed that $\mathrm{H}$. pylori antigens can activate the mucosal immune system and gene translocation, thereby inducing primary gastric lymphoma (5). Clinical manifestations of PGL are usually nonspecific. Main symptoms include epigastric pain, nausea, vomiting and weight loss. Anorexia/ fatigue, bleeding, and palpable mass are less common. The lesion originates from the submucosa, so conventional gastroscopy has limited diagnostic potential (6-8). Endoscopic ultrasonography (EUS) was suitable to identify the depth of invasion in the gastric wall, and to rule out infiltration of surrounding organs and the involvement of the perigastric lymph nodes. Previously, scholars have found out that EUS has a high degree of accuracy for the diagnosis of PGL and an important value in the stage definition, curative effect evaluation, and treatment decisions and is useful for the early detection of recurrence in cases $(9,10)$. Ultrasonography-guided core biopsy can be performed for tissue diagnosis. Therefore, EUS can make up for the deficiency of the conventional gastroscopy. It could potentially be one of the best diagnostic aid to PGL. The aim of this study was to evaluate the diagnosis and follow-up value of EUS in Primary gastric non-Hodgkin's lymphoma (PGL). We present the following article in accordance with the STARD reporting checklist (available at http://dx.doi.org/10.21037/tcr-20-2459).

\section{Methods}

One hundred and four consecutive patients suspicious of PGL by gastroscopy were selected from department of gastroenterology of Ruijin Hospital from January 2017 to December 2019. Seventy-nine of these cases were diagnosed with lymphoma either by EUS and biopsy pathology or by postoperative pathology. All 79 patients met Dawson diagnostic criteria for PGL (11), which are: (I) no enlarged superficial lymph nodes when the patient is first seen; (II) the white blood cell counts, both total and differential, are within normal range and chest radiographs without obvious enlargement of the mediastinal nodes; (III) at laparotomy only regional nodes are affected by disease; and (IV) liver and spleen seem free of tumor. According to the pathologic classification $(3,4), 31$ cases were confirmed as mucosa associated lymphoid tissue B lymphoma type, 38 cases were confirmed as diffuse large B-cell lymphomas, 1 case was Mantle cell lymphoma, 2 cases were follicular lymphomas, 4 cases were marginal zone lymphomas and 3 cases were unclassified B-cell lymphomas. All patients were treated during follow-up. No patients were lost of follow- ups during the study period. The study was conducted in accordance with the Declaration of Helsinki (as revised in 2013). The study was approved by ethics board of Ruijin Hospital (201797) and informed consent was taken from all the patients.

EUS (EG-530UR2 Fujifilm, Japan) and miniprobe sonography (P2615-M Fujifilm, Japan) were performed to evaluate the depth of the lesions and perigastric lymph node. The endoscope is a conventional Fujifilm gastroscope type EG600WR. Patients underwent gastroscopy with gastric biopsies followed by EUS and selected the most significant thickening gastric wall for 5-8 directed excavation biopsies. Patients were admitted to the hospital. All routine blood tests and laboratory findings, including chest X-ray, ECG, abdominal and lymph node ultrasound, abdominal CT and bone marrow biopsy were performed. All patients underwent the 13C-urea breath test (13C-UBT) for assessment of Helicobacter pylori (HP) infection. The depth of invasion in the gastric wall and the detection of regional lymph node involvement in primary gastric lymphoma were evaluated with EUS according to the 7th edition of the International Union Cancer Control (UICC)/ American Joint Committee on Cancer (AJCC) TNM staging system. We analyzed the PGL characteristics and diagnostic accuracy with EUS. In these patients, followup data including efficacy and survival after treatment completion were analyzed. The average follow-up period was 19 months with a range of 5-36 months. Patients were evaluated using EUS with biopsy at baseline and 3-6, 12, 18 and 24 months after the initiation of treatment.

Evaluation criteria include clinical manifestation of PGL, the diagnosis sensitivity of gastroscopic biopsy for PGL, the diagnostic accuracy of gastroscopy with biopsy, the sensitivity, specificity, diagnostic accuracy and lesion features in EUS. According to Suekane's classification, EUS feature of PGL was classified into 4 types: superficially spreading type, diffusely infiltrating type, mass-forming type and mixed type (12). We compared TMN stage by EUS with pathological stage, assessed the H. pylori infection (HPI) rate in PGL patients, histological remission after $\mathrm{H}$ pylori eradication. Patients were followed up for recurrence based on EUS.

\section{Statistical analysis}

Statistical analyses were conducted using SPSS v17 statistical analysis software. Measurement data were expressed as mean \pm standard deviation $(\mathrm{SD})$. Comparison 
Table 1 Patient demographics and clinical characteristics $(n=79)$

\begin{tabular}{|c|c|}
\hline Patient characteristics & No. of patients [\%] \\
\hline \multicolumn{2}{|l|}{ Gender } \\
\hline Male & 50 [63] \\
\hline Female & 29 [37] \\
\hline Age, median [range] & 56 [24-85] \\
\hline \multicolumn{2}{|l|}{ Helicobacter pylori infection } \\
\hline Positive & 70 [89] \\
\hline Negative & $9[11]$ \\
\hline \multicolumn{2}{|l|}{ Site of lesions } \\
\hline Corpus of the stomach & $37[47]$ \\
\hline Antrum & 23 [29] \\
\hline Antral-body junction & 16 [20] \\
\hline Lesser curve & $4[5]$ \\
\hline Fundus & 10 [13] \\
\hline \multicolumn{2}{|l|}{ Dominant endoscopic type } \\
\hline Superficial spreading & 25 [32] \\
\hline Exophytic/Mass-forming & $10[13]$ \\
\hline Ulcerative/Diffuse infiltrating & 31 [39] \\
\hline Mix & $13[16]$ \\
\hline \multicolumn{2}{|l|}{ Tumour invasion } \\
\hline Mucosal & $25[31.6]$ \\
\hline Submucosal & 16 [20.3] \\
\hline Muscularis propria & 17 [21.5] \\
\hline Serosa & $12[15.2]$ \\
\hline Penetrated the serosa & 9 [11.4] \\
\hline
\end{tabular}

between groups was performed using $t$ test. Enumeration data were processed using Chi-square test. $\mathrm{P} \leq 0.05$ was considered statistically significant.

\section{Results}

\section{Clinical manifestations and morphological features}

There were 50 males and 29 females with a male to female ratio of 1.7:1 (Table 1). Participants had a mean age of 56 years (ranging from 24 to 85 years, $\mathrm{SD}=15.1$ years). Clinical symptoms were abdominal pain in 63 cases $(79.7 \%)$, nausea and vomiting in 28 cases (35.4\%), gastrointestinal bleeding in 20 cases $(25.3 \%)$, the appearance of an abdominal mass in
16 cases (20.3\%), weight loss and anemia in 15 cases (19.0\%).

Endoscopic appearances were shallow ulcers and mucosal swelling in 42 cases (53.2\%), space-occupying lesions with ulcers in 30 cases $(38.0 \%)$, multiples shallow ulcers with protruding mass lesion in 7 cases $(8.9 \%)$.

\section{EUS features of PGL}

The involvement site was the corpus of the stomach (37 cases), the antrum (23 cases), antral-body junction (16 cases), the fundus (10 cases) and the lesser curvature (4 cases); lesions were multifocal in 10 patients. Among the 79 patients, superficially spreading type was in $25(31.6 \%)$ patients, diffusely infiltrating type in $31(39.2 \%)$ patients, mass-forming type in $10(12.66 \%)$ patients and mixed type in $13(16.46 \%)$ patients. Each type has different depth of invasion in the gastric wall.

The image of superficially spreading type demonstrates abnormally decreased echogenicity and thickening of the mucosa and submucosa (Figure 1A). The image of massforming type demonstrates localized hypoechoic mass at the third-four layer well demarcated from the surrounding tissue (Figure 1B). The image of diffuse-infiltrative type demonstrates diffuse trans-mural involvement of the gastric wall with irregular layer border and hetero-echogenicity (Figure 1C). The image of mixed-type demonstrates a combination of the previous three types.

In the present study, EUS showed that in all patients the lesion site had been replaced by a hypoechoic thickened gastric wall. Endoscopic ultrasound of the stomach revealed local or diffuse thickening of the gastric wall, average thickness was $(1.4 \pm 0.7) \mathrm{cm}$.

The gastric wall layers were visible in 25 patients, invisible in 54 patients, among whom, eight patients showed hypoechoic gastric wall with heterogeneity in EUS. Tumor invasion was confined to mucosal layer in $25(31.6 \%)$ patients, to mucosal and submucosal layer in 16 (20.3\%) patients. Seventeen cases $(21.5 \%)$ had lesions invading into the muscularis propria layer, 12 cases $(15.2 \%)$ into the serosa and tumors penetrated the serosa in 9 cases (11.4\%). Among those patients, 11 cases were lymph node metastasis positive ( $4 \mathrm{~N} 1$ cases, $7 \mathrm{~N} 2$ cases).

\section{Diagnostic accuracy of EUS}

According to the pathologic classification $(3,4) 31$ cases were confirmed as mucosa associated lymphoid tissue B lymphoma type, 38 cases were confirmed as diffuse large B-cell lymphomas, 1 case was Mantle cell lymphoma, 2 cases were follicular lymphomas, 4 cases were marginal zone lymphomas 

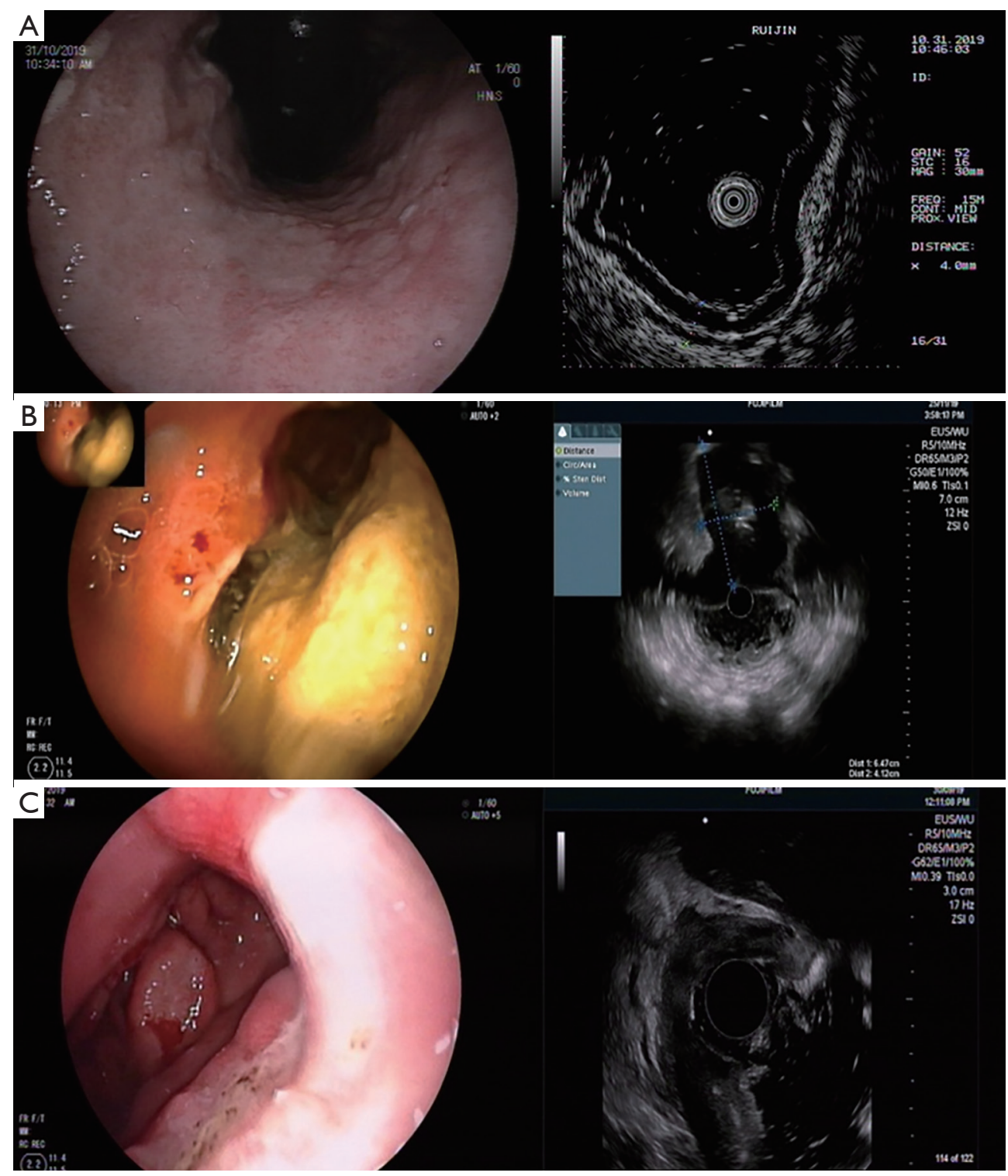

Figure 1 Endoscopic and EUS features of PGL. (A) Superficial spreading type. The lesion is mainly thickened in the mucosal layer, and the submucosa and muscle layer are not thickened. (B) Exophytic/Mass-forming type. The hierarchical structure of the normal stomach wall at the lesion disappeared, replaced by a hypoechoic mass and protruded into the cavity. (C) Ulcerative/Diffuse infiltrating type. The gastric wall is diffusely thickened, and the lesions mainly spread to the mucosal layer and submucosal layer, and the boundary between the local and the muscle layer is not clear. EUS, endoscopic ultrasonography; PGL, primary gastric non-Hodgkin's lymphoma.

and 3 cases were unclassified B-cell lymphomas. Representative photographs of the immunohistochemical features are provided in Figure 2. The sensitivity of PGL made on microscopic evaluation of gastroscopic biopsy specimens was $58.2 \%$ (46/79). The diagnostic accuracy made on microscopic evaluation of gastroscopic biopsy specimens was $57.7 \%$ (60/104). Seventy-four patients were diagnosed PGL with
EUS. Among these patients, targeted deep biopsy specimens were pathologically diagnosed as PGL in 69 cases and poorly differentiated adenocarcinoma in 5 cases (Table 2). We found sensitivity and specificity of EUS combined with deep targeted biopsy as $87.3 \%(69 / 79)$ and $80.0 \%(20 / 25)$ respectively, with $85.6 \%(89 / 104)$ as diagnostic accuracy. The diagnostic accuracy of PGL with deep targeted biopsy under EUS was 

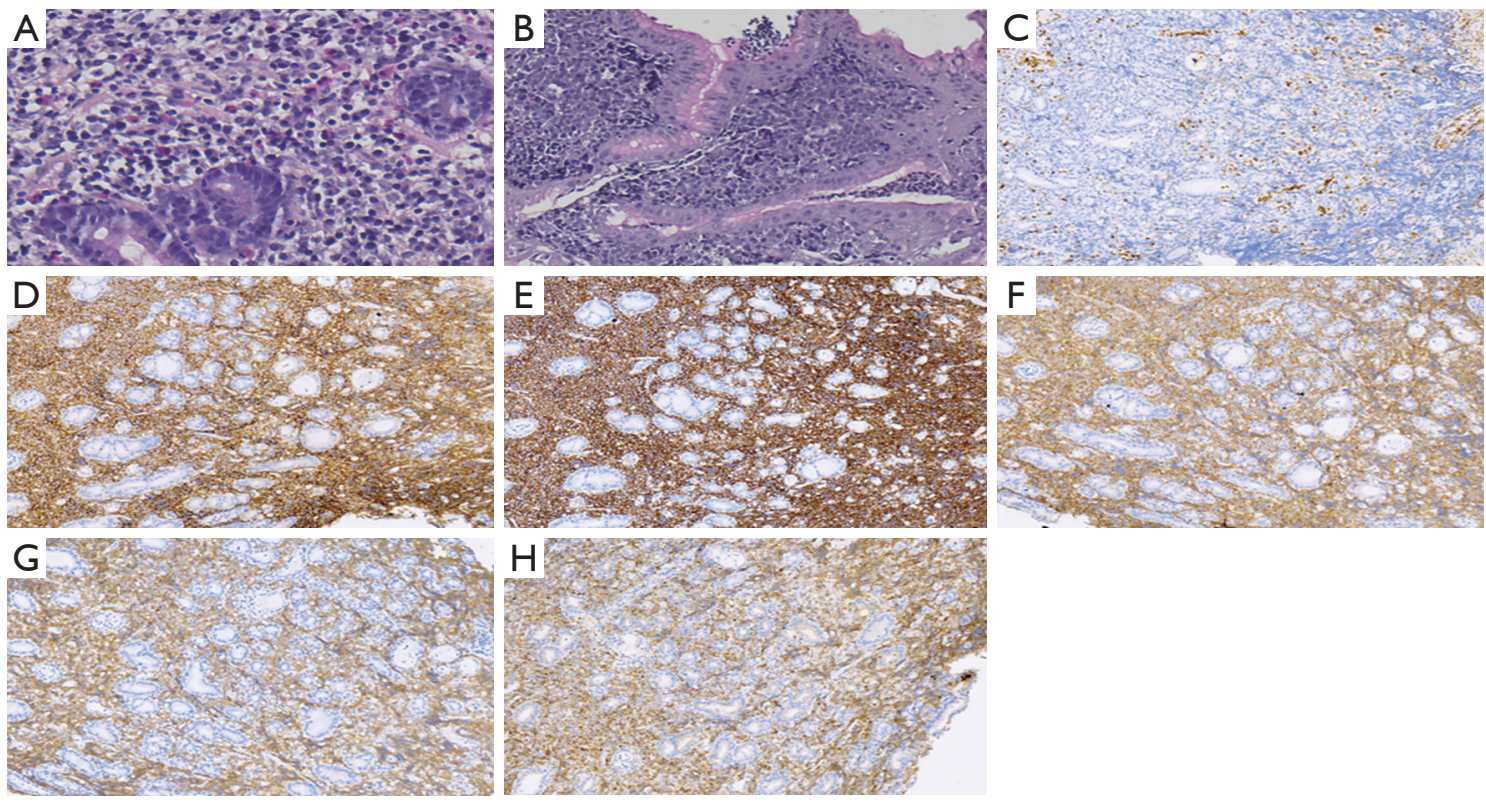

Figure 2 Histological and immunohistochemistry figure. (A) MALT MALT lymphoma cells are rich in cytoplasm, showing a monocyte-like morphology. Tumor cells surround reactive follicles [hematoxylin-eosin staining (HE), 40x]. (B) DLBCL Diffuse distribution of large cells (HE, 20×). (C) Cluster of differentiation (CD) 10. (D) CD 19. (E) CD 20; (F) CD 22. (G) CD 79 . (H) BCl-2 [immunohistochemical staining (IHC), 10x].

Table 2 Diagnosis of conventional gastroscopic biopsy, ultrasound gastroscopy and targeted biopsy under ultrasound endoscopy

\begin{tabular}{|c|c|c|c|c|c|c|c|c|c|c|}
\hline \multirow{2}{*}{$\begin{array}{l}\text { Final pathological } \\
\text { diagnosis }\end{array}$} & \multirow{2}{*}{$\begin{array}{l}\text { Number } \\
\text { of cases }\end{array}$} & \multicolumn{3}{|c|}{ Conventional gastroscopic biopsy } & \multicolumn{3}{|c|}{ Endoscopy ultrasound } & \multicolumn{3}{|c|}{$\begin{array}{l}\text { Endoscopy ultrasound + deep } \\
\text { target biopsy }\end{array}$} \\
\hline & & Lymphoma & $\begin{array}{l}\text { Gastric } \\
\text { cancer }\end{array}$ & $\begin{array}{l}\text { Inflammatory } \\
\text { lesions }\end{array}$ & Lymphoma & $\begin{array}{l}\text { Gastric } \\
\text { cancer }\end{array}$ & $\begin{array}{l}\text { Inflammatory } \\
\text { lesions }\end{array}$ & Lymphoma & $\begin{array}{l}\text { Gstric } \\
\text { cancer }\end{array}$ & $\begin{array}{c}\text { Inflammatory } \\
\text { lesions }\end{array}$ \\
\hline Lymphoma & 79 & 46 & & 33 & 69 & 9 & 1 & 69 & & 10 \\
\hline Gastric cancer & 15 & & 4 & 11 & 5 & 10 & 0 & & 13 & 2 \\
\hline
\end{tabular}

higher than that of gastroscopic biopsy, the difference is statistically significant $(\mathrm{P}<0.001)$. Thirteen patients $(8$ MALT patients and 5 DLBCL patients) were treated with surgical treatment, including those who could not be diagnosed by biopsy and those with pyloric obstruction. The preoperative diagnostic accuracy of $\mathrm{T}$ and $\mathrm{N}$ staging by EUS compared to those by pathological examination of the surgical specimens were 13/13, 11/13 respectively.

\section{Value of Helicobacter pylori eradication in the treatment of H. pylori-associated PGL}

The overall positive rate of $\mathrm{H}$. pylori was $88.6 \%(70 / 79)$ in PGL patients. The positive H. pylori rate was $90.3 \%$ (28/31) in MALT, and $84.2 \%(32 / 38)$ in DLBCL. All H. pyloripositive non-operate patients had eradication therapy. The eradication rate of Helicobacter pylori was $76.3 \%$ (45/59). Among eradicators, 25 cases were superficial type. Most of the patients who had eradication therapy in this study were treated with chemotherapy and/or radiation except 7 patients treated with H. pylori eradication alone among whom 3 recurred in six months. The time needed to achieve complete clinical remission was shorter in patients for whom $H$. pylori eradication was successful (3.2 \pm 0.7 months) than in patients for whom eradication failed (4.5 months \pm 0.8 ). The difference was statistically significant $(\mathrm{t}=4.3, \mathrm{P}<0.001)$.

At the first reexamination with deep targeted biopsy 
under EUS, complete remission rate was $87.0 \%(20 / 23)$ in gastric MALT lymphoma patients, and $27.3 \%$ (9/33) in DLBCL patients. The difference was statistically significant $(\mathrm{P}<0.001)$.

\section{The value of EUS for long-term follow-up for the assessment of efficacy following treatment of PGL}

The follow-up time ranged from 5 to 36 months, with a mean follow-up time of 19 months. All cases underwent deep targeted biopsy under EUS 3 to 6 months first time after treatment. Fifty-two patients presented with reduction in gastric wall thickness and had conserved its five-layer structure and ulcer scar on EUS during the first follow-up after the treatment. Biopsy sampling revealed chronic atrophic gastritis or intestinal metaplasia without pathological evidence of lymphomas or atypical lymphocyte infiltration. The endoscopic ultrasonographic images of 14 partial remission patients' showed heterogeneous hypoechogenic lesions and replacement of gastric wall layer structure with abnormal local gastric wall thickening. Biopsy sampling revealed atypical lymphocyte infiltration. Immunohistochemical examination showed residual lymphoma. Recurrence confirmed by EUS occurred at 6 months after complete remission in 3 patients who received only Helicobacter pylori eradication therapy. These patients were treated with additional chemotherapy, and the disease complete remission was confirmed by histopathological analysis of deep targeted biopsy under EUS 12 months after chemotherapy. Seven patients (including 6 DLBCL patients and 1 MALT patient) in remission that relapsed after 18 to 24 months were treated with chemotherapy. All patients were still alive at the last time of follow-up, including six patients receiving intermittent consolidation chemotherapy regimens.

\section{Discussion}

This study included 79 patients with PGL confirmed by pathology. Their clinical characteristics are basically consistent with those reported by Andriani et al. (13). Endoscopic findings show slight ulceration, the presence of a mass or a polypoidal lesion with or without an ulcer or mucosal swelling in some cases. PGLs usually arise in layer 2, 3, or 4, and the forceps usually used for biopsy sampling often will not reach the deep layer of mucosa. Therefore, it will sometimes be difficult to histologically diagnose the disease. In the current study, the detection rate of PGL made on microscopic evaluation of gastroscopic biopsy specimens was $58.2 \%$, which might be a result of the failure to adequately expose the tumor for the biopsy forceps to reach. EUS can provide a precise description of the abnormalities present in a specific gastric wall layer, and integration with targeted biopsy leads to improvement in detection rate. According to Suekane's classification (12), superficially spreading type (31.6\%) and diffusely infiltrating type $(39.2 \%)$ are predominant EUS features of PGL in the present study. PGL lesions with mucosal and submucosal involvement spread horizontally, this phenomenon reflects the biological characteristics. Some scholars found that MALT lymphoma limited to mucosa responds well to $\mathrm{HP}$ eradication therapy. Among all study population, 59 patients received $H$. pylori eradication therapy, Helicobacter pylori eradication rate was $76.3 \%$. Twenty-five cases with superficial type lesion that mainly located within the mucosa were eradicated in all of them. Thus, EUS is in favor of prediction of response to Helicobacter pylori eradication therapy. Further study is needed to validate the EUS as one of the most valuable indicators to predict the probability of response to antibiotic therapy (in case of MALT lymphoma).

We concluded from our studies that EUS (85.6\%) improved diagnostic accuracy in comparison with gastroscopy (44.2\%). Polypoid PGL lesions are often confused with adenocarcinoma, whereas diffuse infiltrative type lymphomas often mimic the picture of linitis plastica (14). Five patients whose biopsy specimen pathology were adenocarcinoma were diagnosed with gastric PGL by EUS. It appears that there are some structural similarities between these two diseases in term of ultrasonic imaging characteristics. TruCut needle biopsy or fine needle aspiration biopsy under ultrasonic guidance can effectively obtain pathological diagnosis including cytological and histological analyses but comparatively high requirements for operators' technical skills and high cost limit its uses. Deep targeted biopsy sometimes miss diagnosis due to insufficient depth. EUS can detect perigastric lymph node involvement but can't offer information and access to distant lymph nodes due to the limitation of its scanning coverage. In the operated patients, the accuracy of $\mathrm{N}$ stage by preoperative EUS was $12 / 13$ while $\mathrm{T}$ staging has been able to reproduce the same data as the pathological $\mathrm{N}$ staging. Thus, EUS is a promising procedure to measure the entirety of gastric wall involvement and to detect perigastric lymph node involvement.

Helicobacter pylori infection (HPI) plays an important role in the pathogenesis of PGL. At present, the most widely accepted initial therapy for early stage MALT lymphoma is eradication of HPI (15). Those patients who initially had 
successful Helicobacter pylori eradication had a shorter time to complete remission than those who had eradication failure. There are various reports showing that the $\mathrm{H}$. pylori eradication regimen is effective for MALT lymphoma, which may be related to reduction of mucosal inflammatory reactions. In the current study, there were 3 cases of gastric MALT lymphoma recurrence confirmed by EUS 6 months after eradication of $\mathrm{H}$. pylori. Continuous follow-up is necessary to monitor for recurrence.

The diagnostic value of EUS in PGL has been widely accepted and recognized, but there is no uniform protocol for the evaluation and follow-up of the patients with PGL. The normalization of EUS pattern has a delay compared with histological findings $(16,17)$. Therefore, post-treatment EUS evaluations have not generally been recommended for the response assessment. One of the major issues in the use of EUS in assessing the response to therapy is that EUS will document regression of endosonographic abnormalities with considerable delay compared with the histologic findings (18-20). Nevertheless, most researchers think that EUS has an important value in the long-term follow-up of PGL by evaluation for gastric wall lesions, response to drug treatment and early detection of tumor recurrence $(21,22)$.

In conclusion, EUS combined with deep targeted biopsy has a high sensitivity and specificity in the diagnosis and staging of tumors to guide further intervention. At present, the most widely accepted initial therapy for localized disease is aimed at the eradication of HPI (21). Close followup is very important. The European Society for Medical Oncology (ESMO) group has suggested performing strict endoscopic follow-up with multiple biopsy specimens taken 2 to 3 months after treatment and then twice annually for 2 years so as to detect early relapse and have impact on clinical practice (19).

\section{Acknowledgments}

Funding: This study was supported by Shanghai Sailing Program (20YF1428200) and Shanghai Municipal Health Commission (No. 201640112).

\section{Footnote}

Reporting Checklist: The authors have completed the STARD reporting checklist. Available at http://dx.doi.org/10.21037/ tcr-20-2459

Data Sharing Statement: Available at http://dx.doi. org/10.21037/tcr-20-2459

Peer Review File: Available at http://dx.doi.org/10.21037/tcr20-2459.

Conflicts of Interest: All authors have completed the ICMJE uniform disclosure form (available at http://dx.doi. org/10.21037/tcr-20-2459). Dr. RF reports other from Shanghai Health and Family Planning Committee (No. 201640112), during the conduct of the study. Dr. TZ reports other from Shanghai committee of Science and Technology, during the conduct of the study. The other authors have no conflicts of interest to declare.

Etbical Statement: The authors are accountable for all aspects of the work in ensuring that questions related to the accuracy or integrity of any part of the work are appropriately investigated and resolved. The study was conducted in accordance with the Declaration of Helsinki (as revised in 2013). The study was approved by ethics board of Ruijin hospital (201797) and informed consent was taken from all the patients.

Open Access Statement: This is an Open Access article distributed in accordance with the Creative Commons Attribution-NonCommercial-NoDerivs 4.0 International License (CC BY-NC-ND 4.0), which permits the noncommercial replication and distribution of the article with the strict proviso that no changes or edits are made and the original work is properly cited (including links to both the formal publication through the relevant DOI and the license). See: https://creativecommons.org/licenses/by-nc-nd/4.0/.

\section{References}

1. Fischbach W. Long-term follow-up of gastric lymphoma after stomach conserving treatment. Best Pract Res Clin Gastroenterol 2010;24:71-7.

2. Koch P, Probst A, Berdel WE, et al. Treatment results in localized primary gastric lymphoma: data of patients registered within the German multicenter study (GIT NHL 02/96). J Clin Oncol 2005;23:7050-9.

3. Zucca E, Roggero E, Bertoni F, et al. Primary extranodal non-Hodgkin's lymphomas. Part 1: Gastrointestinal, cutaneous and genitourinary lymphomas. Ann Oncol 1997;8:727-37.

4. Zucca E, Roggero E, Bertoni F, et al. Primary extranodal non-Hodgkin's lymphomas. Part 2: Head and neck, central 
nervous system and other less common sites. Ann Oncol 1999;10:1023-33.

5. Swerdlow SH CE, Harris NL, et al. WHO Classification of Tumours of Hematopoietic Lymphoid Tissues. 4th ed. Lyon: International Agency for Research on Cancer, 2008:214-7.

6. Gines A, Pellise M, Fernandez-Esparrach G, et al. Endoscopic ultrasonography in patients with large gastric folds at endoscopy and biopsies negative for malignancy: predictors of malignant disease and clinical impact. Am J Gastroenterol 2006;101:64-9.

7. Karaca C, Turner BG, Cizginer S, et al. Accuracy of EUS in the evaluation of small gastric subepithelial lesions. Gastrointest Endosc 2010;71:722-7.

8. Nagler AK, Aslanian HR, Siddiqui UD. Endoscopic ultrasound and gastric lesions. J Clin Gastroenterol 2011;45:215-21.

9. Caletti G, Fusaroli P, Bocus P. Endoscopic ultrasonography. Digestion 1998;59:509-29.

10. Palazzo L, Roseau G, Ruskone-Fourmestraux A, et al. Endoscopic ultrasonography in the local staging of primary gastric lymphoma. Endoscopy 1993;25:502-8.

11. Dawson IM, Cornes JS, Morson BC. Primary malignant lymphoid tumours of the intestinal tract. Report of 37 cases with a study of factors influencing prognosis. Br J Surg 1961;49:80-9.

12. Suekane H, Iida M, Yao T, et al. Endoscopic ultrasonography in primary gastric lymphoma: correlation with endoscopic and histologic findings. Gastrointest Endosc 1993;39:139-45.

13. Andriani A, Zullo A, Di Raimondo F, et al. Clinical and endoscopic presentation of primary gastric lymphoma: a multicentre study. Aliment Pharmacol Ther 2006;23:721-6.

Cite this article as: Fan R, Zhang T, He X, Wu W, Gong T, Lu H, Cheng S, Zhong H, Cao W. Diagnosis and follow-up value of endoscopic ultrasonography (EUS) in primary gastric non-Hodgkin's lymphoma. Transl Cancer Res 2021;10(2):10881095. doi: 10.21037/tcr-20-2459
14. Fork FT, Haglund U, Hogstrom H, et al. Primary gastric lymphoma versus gastric cancer. An endoscopic and radiographic study of differential diagnostic possibilities. Endoscopy 1985;17:5-7.

15. Komoto M, Tominaga K, Nakata B, et al. Complete regression of low-grade mucosa-associated lymphoid tissue (MALT) lymphoma in the gastric stump after eradication of Helicobacter pylori. J Exp Clin Cancer Res 2006;25:283-5.

16. Puspok A, Raderer M, Chott A, et al. Endoscopic ultrasound in the follow up and response assessment of patients with primary gastric lymphoma. Gut 2002;51:691-4.

17. Di Raimondo F CL, Bonanno G, et al. Is endoscopic ultrasound clinically useful for follow-up of gastric lymphoma? Ann Oncol 2007;18:351-6.

18. Ruskone-Fourmestraux A, Fischbach W, Aleman BM, et al. EGILS consensus report. Gastric extranodal marginal zone B-cell lymphoma of MALT. Gut 2011;60:747-58.

19. Zucca E, Dreyling M, Group EGW. Gastric marginal zone lymphoma of MALT type: ESMO Clinical Practice Guidelines for diagnosis, treatment and follow-up. Ann Oncol 2010;21 Suppl 5:v175-6.

20. Vetro C, Chiarenza A, Romano A, et al. Prognostic assessment and treatment of primary gastric lymphomas: how endoscopic ultrasonography can help in tailoring patient management. Clin Lymphoma Myeloma Leuk 2014;14:179-85.

21. Hoepffner N, Lahme T, Gilly J, et al. Endoscopic ultrasound in the long-term follow-up of primary lymphomas of the stomach under conservative therapy. $\mathrm{Z}$ Gastroenterol 2003;41:1151-6.

22. Zucca E, Cavalli F. Are antibiotics the treatment of choice for gastric lymphoma? Curr Hematol Rep 2004;3:11-6. 